\title{
Research on Quality Risk of EPC Hydropower Projects in Vietnam
}

\author{
Sy Hung Mai ${ }^{1,2 *}$, Jianqiong Wang ${ }^{1}$ \\ ${ }^{1}$ School of Economics and Management, Southwest Jiaotong University, Chengdu, China \\ ${ }^{2}$ Department of Hydraulic Engineering and Construction, National University of Civil Engineering, Hanoi, Vietnam \\ Email: hungms@nuce.edu.vn, *maihungdvh@gmail.com
}

How to cite this paper: Mai, S.H. and Wang, J.Q. (2017) Research on Quality Risk of EPC Hydropower Projects in Vietnam. World Journal of Engineering and Technology, 5, 299-308.

https://doi.org/10.4236/wjet.2017.52024

Received: April 28, 2017

Accepted: May 22, 2017

Published: May 25, 2017

Copyright ( 92017 by authors and Scientific Research Publishing Inc. This work is licensed under the Creative Commons Attribution International License (CC BY 4.0).

http://creativecommons.org/licenses/by/4.0/

cc) (i) Open Access

\begin{abstract}
Engineering, procurement and construction (EPC) contracts are on the way to become the most usual form of contracting applied by the private sector to undertake construction works on large scale Hydropower projects. If EPC contract management is not implemented and controlled properly. Quality is the first important factor for any contractors who involve in the hydropower project execution. The purpose of this study is to investigate and evaluate risks causing not good quality of EPC hydropower projects in Vietnam. In addition, the study also provided the recommendations for project practitioners to mitigate the impacts of those identified risks. The findings of this study can be a good managerial reference for project management teams who are working in other countries that have similar economic and investment environments to Vietnam to get their EPC construction project completed on quality, thus will ensuring the benefits to the government, the investors, the contractors, and the parties involved.
\end{abstract}

\section{Keywords}

EPC Hydropower Project, Risk Analysis and Evaluation, Risk Control, Prevent Risks

\section{Introduction}

Generally, in different countries, there are numerous different factors leading to not good quality of contracting process. For instance, Assaf, S. A., Al-Khalil, M., and Al-Hazmi, M. (1995), "Causes of delay in large building construction projects." [1]. Chan et al. presented results of a survey undertaken to determine and evaluate the relative importance of quality in Hong Kong construction projects (Chan and Kumaraswamy, 1997) [2]. The survey covered 83 previously identified delay factors, which were grouped into eight major categories. Koushki, P., 
Al-Rashid, K., and Kartam, N. (2005), "Delays and cost increases in the construction of private residential projects in Kuwait." Construction Management and Economics, 23(3), 285-294 [3]. Faridi, A. S., and El - Sayegh, S. M. (2006), "Significant factors causing delay in the UAE construction industry." [4]. Otherwise, Murali et al. through analysing reasons that cause not good quality and delay of construction industry in Malaysia (Sambasivan and Soon, 2007) [5]. The author presented 10 most important causes of delay from a list of 28 different causes and 6 different effects of delay. In addition, Doloi et al. identified the key factors impacting delay in Indian construction industry and established the relationship between the critical attributes for developing prediction models for assessing the impacts of these factors on not good quality and delay using questionnaire and personal interviews (Doloi, Sawhney, Iyer and Rentala, 2012) [6]. The authors therefore presented 7 most critical factors of not good quality and construction delay.

Regarding to EPC hydropower projects, despite of its quality risk is also influenced by a variety of factors that are different from various countries, but previous researches have improperly focused on this topic. For instance, Wang et al. through evidences from Chinese constructions companies have quantitatively investigated the cause-effect relations among partnering, design management, and project outcomes then concluded that design management is critical to project performances (Wang, Tang, Qi, Shen and Huang, 2015) [7]. However, the research does not show mutual interactions among design, procurement, and construction risks. Shi et al. also presented a comprehensive assessment of power projects overseas investment risks by establishing risk assessment model (Ge and Shi, 2014) [8]. Zhao et al. studied uncertainty runs through the whole process of the construction of the hydropower projects by analysing influencing factors of the risk of the hydropower projects (Zhao and Jia, 2011) [9], based on the analytic hierarchy process and the theory of intuitionistic fuzzy sets, an example which shows the practicality and validity of the method and also supplies scientific bases and references to the hydropower projects capitalists to make their investment decisions. Nevertheless, these researches merely presented most common assessment with respect to risk management of the projects, but mention to unique characteristics of EPC hydropower projects and present risks that mainly influence on schedule delay of those kinds of projects. Research on assessment of risks influence on schedule delay of EPC hydropower projects for every country is indeed necessary. Wang et al. have presented 22 risk elements grouped into 5 groups including environment, technology, finance, and management to assess indicators of risks (Wang, Liu and Zhu, 2012) [10]. However, these indicators are not suitable to comprehensively assess the influence of risks on schedule delay of EPC hydropower projects in the developing countries of Asia. Liu et al. attempted Carlo method to deal with random variables in order to manage financial risks, compensation, and financial management in construction process (Liu and Song, 2010) [11]. Li has presented 27 risks elements grouping into 8 groups to assess influence of risks on projects as well as pro- 
posed most common risks including in international EPC hydropower projects (Li, 2012) [12]. However, detailed and accuracy assessment on risks influencing on EPC hydropower projects is depended on characteristics and developing level of specific country.

The EPC contracting process of the hydropower projects in the developing countries of Asia is now facing many difficulties. Through analyses mentioned in preceding part, one can obviously realize that studies on risks of hydropower projects in the developing countries of Asia are still limited. Recently, researchers have gradually focused on risk management of hydropower projects in the developing countries of Asia. For instance, Chao et al. analysed risks in EPC hydropower projects in Vietnam, presented risk factors, and suggested ways to minimize risks and proposed management measures (Chao, 2008) [13]. The study has revealed that execution of EPC project in Vietnam is really complicated, occurrences of risks exist in different ways. Based on these foundations, we could properly build the practical risk management and risk control strategy for EPC project in Vietnam. Li Wei through a research with respect to risk management for international hydropower engineering of EPC program, which located at Con's river in Vietnam, mentioned that financial and environmental risks significantly influence on process of project $(\mathrm{Li}, 2012)$. Chen et al. have conducted a research on risk assessment for EPC hydropower projects and mentioned that construction process of hydropower project is extreme long under complicated conditions (Chen, Liu and Xiao, 2015). Mai et al., through risk evaluation and control of EPC hydropower construction project in Vietnam, have analysed 7 risk factors including 17 main risk elements influence on schedule delay of construction process of EPC hydropower project in Vietnam and developed strategies for project risk allocation and precautions to reduce schedule risk (Hung and Wang, 2016) [14].

On average, the study of quality risk in EPC hydropower construction in Vietnam is very little. The purpose of this study is to investigate and evaluate risks causing not good quality of EPC hydropower projects in Vietnam. In addition, the study also provided the recommendations for project practitioners to mitigate the impacts of those identified risks. With the reality of Poor quality in construction projects, in this study, we present a research on risks involved in Poor quality construction of the hydropower project using EPC mode in Vietnam. We conduct on-site interviews with experts and officers participating in EPC projects to survey. Based on these opinions, we hypothesize then calculate risk factors statistically in order to analyse evaluation synthesis and classify how strong impact of each risk to the Poor quality of EPC hydropower construction project in Vietnam. Our research would contribute to the monitoring of construction quality and successful implementation.

\section{Method Using in the Study}

To date, there are many methods relevant to assessment risk. For instance, surveyed questionnaire combined with guidance of experts (checklist method), 
analytic hierarchy process (AHP), fuzzy set, Mote Carlo simulation, and Carlo methods. In this study, we use checklist method to survey participants who have experiences in EPC hydropower construction in order to assess risks as well as impact level of them on constructions process [15] [16] [17].

The method using in the study is based on the questionnaire including risk elements impact on EPC hydropower projects Vietnam. The entire researched process using in the study is detailed as shown in Figure 1.

To reach the purpose of the study, we use surveyed questionnaire method, the steps are described as follow. Firstly, in order to identify the risks we establish a surveyed questionnaire by means of referencing literatures reported by previous researches. After obtaining an initial surveyed questionnaire with initial risk elements, we deliver the questionnaire to 20 experts who have a lot of experiences in the field related to management risks of EPC hydropower projects to ask their views with respect to the reliability of the questionnaire, then Analysis and assessment risks and Discussions and implications to reduce/prevent risks.

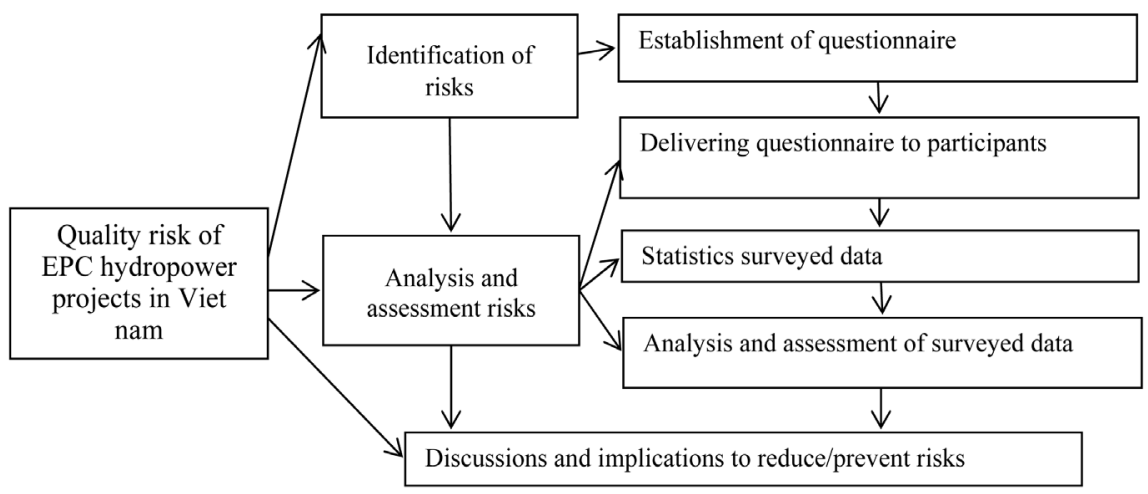

Figure 1. Schematic diagram of method used in the study.

\section{Results}

\subsection{Identification of the Risks}

As Results of risk perception has been presented in "Research on delay risks of EPC hydropower construction projects in Vietnam" of Sy Hung Mai. et al. (Public in 2016, Vol 4, no 4: 9-16.), the author of this distribution will cite previous studies that have identified the risks involved, then will summarize the quality risk factors that affect the main project delays hydropower EPC in Vietnam. The Results are tabulated in Table 1.

\subsection{Analysis, Discussions and Implications to Reduce/Prevent Risks}

Control each section of the project strictly: In bidding period, the technical tender of the general must allow adequate leeway for the design, equipment procurement and construction of implementation phase.

1) Quality control for designing in EPC hydropower projects in Vietnam 
Table 1. Results of risks Identification.

\begin{tabular}{c}
\hline Factor \\
Engineering \\
$\begin{array}{c}\text { Risk due to poor quality of technical design } \\
\text { Risk due to poor quality of construction drawings } \\
\text { Risk due to negative survey data } \\
\text { Risk due to poor inspection of technical and drawings design }\end{array}$ \\
Rrocurement \\
Risk due to uncertain and unclear of purchase contract terms \\
Risk due to poor purchasing materials, \\
supplies, equipment and machines \\
Risk due to poor equipment installation and commissioning \\
Risk due to quality construction projects monitoring team \\
Risk due to construction safety \\
Risks due to poor quality management of investor \\
Risks due to poor quality management of EPC general contractor \\
Risks due to the unclear circular guiding of quality management laws \\
Risk due to poor sub-contractors \\
Risk due to poor construction from the EPC general contractors \\
\hline
\end{tabular}

In the Design phase, "the value engineering" should be used to optimize design, reduce costs rationally on the premise of meeting owner's requirement and make function and cost reach the scientific disposition.

The quality control for engineering shall be listed in following main points.

Firstly, the engineering should be complied with the requirements of national management standard, and the technical data of the project which is launched. The engineering outcome should fulfill the requirements in each stage following the information edited by the Employer; in the meantime the engineering should follow the rules and regulations in national or local grade; follow the national standard in the technical application, or apply the national standard for technical standard to survey and proceed the engineering. It is hence resulted to the satisfaction of the Employer's target as well as ensure the safety, saveness and application of modern and other purposes.

Secondly, the quality management of engineering should abide by "strictly magneemtn and quality ensure". In theory, the entire process of survey and engineering shall be supervised by the Employer, project evaluation meeting organization, technical and design survey, etc. The engineering should focus on the main technical matters supervision which is carried oyt by technical supervisor to define and give out solutions.

One more time, EPC Contractor should inspect the quality regularly or suddenly with the main content: good quality, perfect, specifications to meet the relevant regulations as well as ensure the compatibility of design documentation (design drawings, design report, design requirements, or other design notice), show clearly the connection between designing items; the total value of investment when the project is finished is correct. Other changes in the design step should be agreed by the Employer. The drawing should be approved in the completeness and quality.

Lastly, the evaluation of the independent verification unit must be conducted, indicating that the assessments are: redundant design, conflicting drawings, de- 
ficiencies, errors, and other apparent design flaws that lead to duplicate of procurement of equipment, technical modifications and economic loss or delay of construction, to determine liability for the extent of the loss, and to be punished according to contractual provisions.

2) Quality control for procurement in EPC hydropower projects in Vietnam

Under the proposal of the above risk control and restraint, the author suggests that: For all risks of the EPC hydropower project during implementation, the general contractor must take reasonable measures to minimize the Procurement risks. Firstly, to manage the quality and progress of the procurement, depending on the actual situations of the project, accept the risks and possibilities against the risks of the contractor to take appropriate countermeasures; the goal is without construction extension and increase of construction costs.

\subsection{Quality Management for Procurement}

1) Establish of a management board for cargo purchased which shall handle all the procurement matters. The cargoes quality shall be controlled from the engineering step, procurement, payment, testing, delivery, and reservation. The procurement formalities shall be designated step by step and well planed so that the quality of process shall be supervised entirely. It also should to use all necceassy solutions to ensure the purchased cargo quality so that they shall fulfill the required technical standards as well as other defined documents, and in the meantime, it should be complied with the project technical data requirements and safety rules also once the project is brought into operation.

2) Prepare of requisition documents to meet the designation requirements for each type of cargo group, e.g.: Specificiations of equipment to be handed over to the Manufacturer.

3) Issue manual documents, standards, regulations, formalities for each item procurement. Prepare procurement plan, procurement scope in clear items and assign for clear staffs for each job with the assurance of procurement process (include quality control rules and safety rules as well as methods to ensure such principles).

4) Establish of procurement group which is in charge of investigate and evaluate contractors (who are compatible), prepare contract, check the equipment manufacture timeline, ask the manufacturer to follow the planed schedule, or finish their jobs by the due date to avoid any delays that might affect to the whole progress; produce, inspect, verify, and purchase materials for production, processing, installation, assembly, testing centre, machine capacity testing, painting test, package, transportation and hand-over at site.

5) The supervisor should regularly visit cargoes manufacturer or send one staff to supervise the whole process to make sure that the quality of the outcome shall meet the requirements.

The responsibility of materials, equipment quality: the supplier of equipment and the subcontractors should be responsible under the law on the match of the supplied equipment with the requested one by the Employer (mentioned in the 
supply contract) and must be responsible under the law in terms of quality and compability of such.

Before bringing the matrials, equipment into processing, or assembly progress at site, the contractor has to submit the sample and have the specifications of such approved. The sample and specifications should be archived at the working office of the Employer at site. The specifications (functional characters) should be printed in documents as Mill Test Certiciate and must be the official one to be provided by the supplier. In case of using copy version, the legal resposentative of the supplier should sign on such copy as well as stamp on it then once the Emlpoyer accept, it shall be deemd as the official document between two parties. All the changes during the execution progress should be re-approved by the Employer (with the condition that it must guarantee the requested quality standard).

3) Quality control for construction in EPC hydropower projects in Vietnam

Quality Risk Management Methodology for the EPC Hydropower Project, show in Figure 2.

Firstly, let's start preventing risks that caused by poor quality, cary out the subcontractor quality control system verification, analyze quality defects of the past, and take measures to prevent "recurrence." Learning from other technical quality management experiences, establish a quality assurance system, enhance employee training on career skills, create a positive business culture, Pursue deeply the meaning of quality excellence.

Secondly, during the processing of construction, quality management, each step should be supervised carefully so that the quality control might be carried out correctly and effectively.

Supervising the construction process and accessing acceptance of construction results. The quality control is deemed as the centre of the control progress that ensures the quality of working procedures and define the core or weak section. In order to control quality, and analysis in general in front of reasons that makes the quality problems happened, then build up strategies and controllable methods.

In order to control the quality of the construction progress, and different stages of construction progress in details should prepare quality targets as well as quality ratios as a quality criteria wholy or partly of the assignment to persons; supervision increasing, strictly checking on the building materials quality as per the contractual or design requirements, also relevant lawful rules or industrial construction supervision standard.

Each stage of the construction quality acceptance: Once the quality does not fulfill the requirements, upon analyzing the reasons, the in-charge persio shall organize to recover until the quality is acceptable.

On items of the projects that are finished, it is required to carry out quality inspection strictly. The leader of supervision team shall be responsible for the supervision progress. In order to make a strict supervision, it should be nominated which one is finished as per the quality standard of the project and accepted, and move to next stge. Besides, there are some place which are hard to 


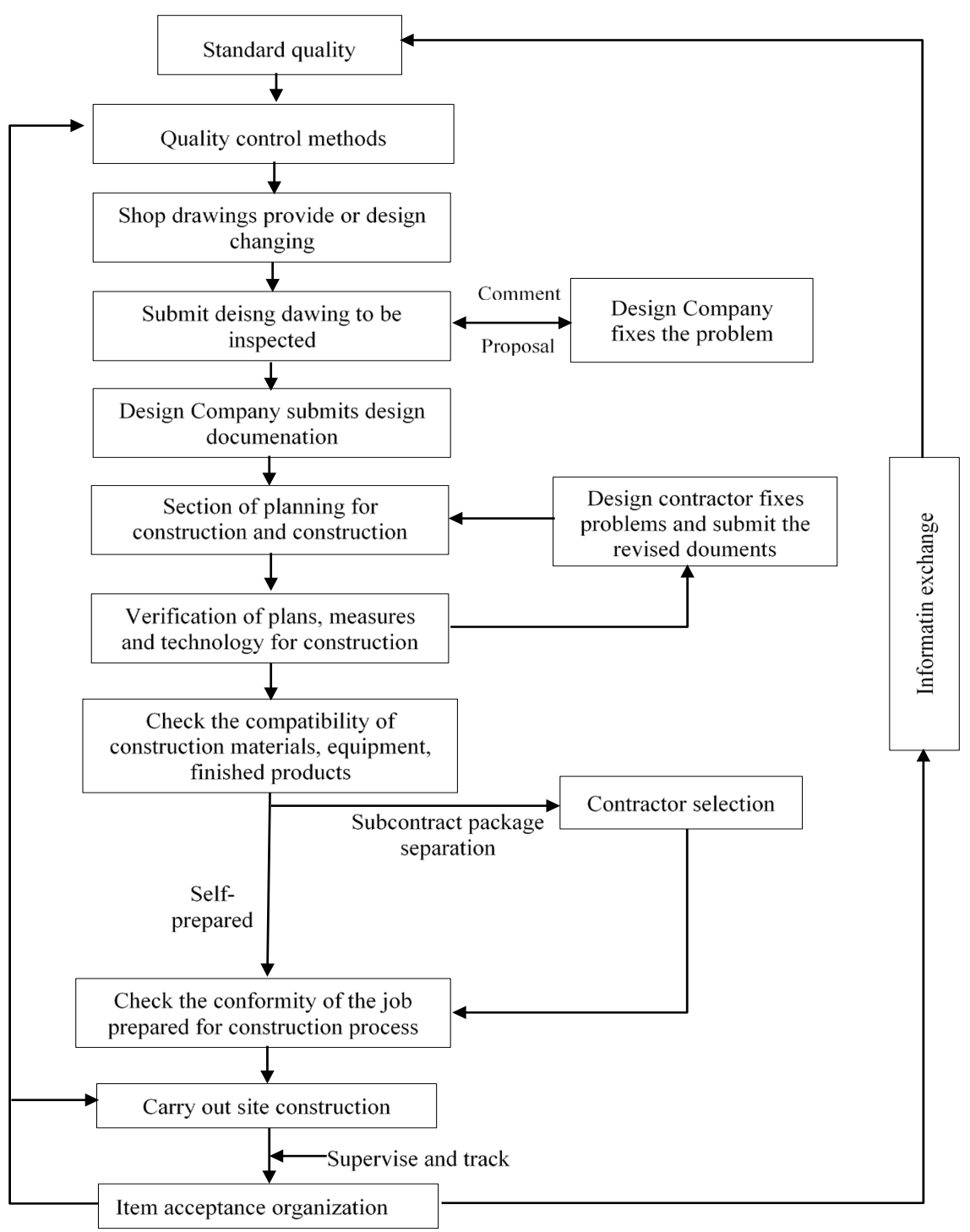

Figure 2. Diagram for quality control for construction of hydropower projecy in Vietnam.

inspect in a project of hydropower like concrete pouring for dam or underground products, etc... in order to ensure the quality, the inspector should check carefully, not to avoid the dangerousness and in the meantime, based on testing and rating ratios to clear the acceptance.

\section{Conclusions}

Quality is the first important factor for any contractors who involve in the hydropower project execution. The EPC contractors should manage well the quality of the project in the stage of construction progress which is deemed to be a core mission of project risks management and that is also might be the main factor which decides the success or failure of such project.

Using surveyed method combining with statistical analysis, the study investigates potential risks influencing on schedule delay of construction quality of 
EPC hydropower projects in Vietnam. Findings in the study includes following achievements:

1) Identification risks that impact on Quality of EPC hydropower construction projects.

2) Based on those risks, the study has analysed and evaluated carefully the risks of determine causes leading to the poor quality of the project.

3) Discussions and implications to reduce/prevent risks.

Quality construction methods for construction stage are important parts of project quality management which required the contractors to abide by the technical contract to develop the quality management system as well as quality system documentation with transparent quality target.

\section{References}

[1] Assaf, S.A., Al-Khalil, M. and Al-Hazmi, M. (1995) Causes of Delay in Large Building Construction Projects. Journal of Management in Engineering, 11, 45-50. https://doi.org/10.1061/(asce)0742-597x(1995)11:2(45)

[2] Chan, D.W. and Kumaraswamy, M.M. (1997) A Comparative Study of Causes of Time Overruns in Hong Kong Construction Projects. International Journal of Project Management, 15, 55-63.

[3] Koushki, P., Al-Rashid, K. and Kartam, N. (2005) Delays and Cost Increases in the Construction of Private Residential Projects in Kuwait. Construction Management and Economics, 23, 285-294. https://doi.org/10.1080/0144619042000326710

[4] Faridi, A.S. and El-Sayegh, S.M. (2006) Significant Factors Causing Delay in the UAE Construction Industry. Construction Management and Economics, 24, 11671176. https://doi.org/10.1080/01446190600827033

[5] Sambasivan, M. and Soon, Y.W. (2007) Causes and Effects of Delays in Malaysian Construction Industry. International Journal of Project Management, 25, 517-526.

[6] Doloi, H., Sawhney, A., Iyer, K. and Rentala, S. (2012) Analysing Factors Affecting Delays in Indian Construction Projects. International Journal of Project Management, 30, 479-489.

[7] Wang, T., Tang, W., Qi, D., Shen, W. and Huang, M. (2015) Enhancing Design Management by Partnering in Delivery of International EPC Projects: Evidence from Chinese Construction Companies. Journal of Construction Engineering and Management, 142, Article ID: 04015099. https://doi.org/10.1061/(ASCE)CO.1943-7862.0001082

[8] Ge, S.J. and Shi, A.N. (2014) Construction of the Factors Affecting China's Hydropower Projects and Overseas Investment Risk Assessment Index System. Applied Mechanics \& Materials, 672-674, 2077-2084.

[9] Zhao, E. and Jia, X. (2011) Research on the Method of Evaluating Risks of Hydropower Project. 2011 International Conference on Computer Science and Service System (CSSS), Nanjing, 27-29 June 2011, 1653-1655.

[10] Wang, L., Liu, J.-L. and Zhu, J.-W. (2012) Risk Evaluation of International EPC Hydropower Project Based on AHP-MF Model. Journal of Engineering Management, 4, 82-86.

[11] Liu, D. and Song, H. (2010) Risk Analysis and Comprehensive Evaluation of Risks in EPC Hydropower Engineering. Water Sciences and Engineering Technology, 1, 32. 
[12] Li, W. (2012) Study on the Risk Management for International Hydropower Engineering of EPC Program. Doctor Thesis, Dalian University of Technology, Dalian.

[13] Chao, J. (2008) A Brief Study on the Risk Management of the Vietnamese Hydropower Project Contract. Enterprise Science and Technology \& Development, 20, 42-45.

[14] Hung, M.S. and Wang, J.Q. (2016) Research on Delay Risks of EPC Hydropower Construction Projects in Vietnam. Journal of Power and Energy Engineering, 4, 916. https://doi.org/10.4236/jpee.2016.44002

[15] Chen, Z., Liu, H. and Xiao, F. (2015) Risk Assessment for EPC Procurement of Hydropower Projects. Yangtze River, 5, 26.

[16] Taylor, S.A., Sharland, A., Cronin, J.J. and Bullard, W. (1993) Recreational Service Quality in the International Setting. International Journal of Service Industry Management, 4, 68-86. https://doi.org/10.1108/09564239310044316

[17] Cohen, J. (1977) Statistical Power Analysis for the Behavioral Sciences. Revised Edition, Academic Press, New York.

\section{Scientific Research Publishing}

Submit or recommend next manuscript to SCIRP and we will provide best service for you:

Accepting pre-submission inquiries through Email, Facebook, LinkedIn, Twitter, etc. A wide selection of journals (inclusive of 9 subjects, more than 200 journals)

Providing 24-hour high-quality service

User-friendly online submission system

Fair and swift peer-review system

Efficient typesetting and proofreading procedure

Display of the result of downloads and visits, as well as the number of cited articles

Maximum dissemination of your research work

Submit your manuscript at: http://papersubmission.scirp.org/

Or contactwjet@scirp.org 